\title{
Gender difference in the association between cough severity and quality of life among patients with postinfectious cough
}

Wei Liu ${ }^{1,3}$, Qinqin Wu², Bing Mao ${ }^{1}$ and Hongli Jiang ${ }^{1 *}$ (D)

\begin{abstract}
Background: Despite close link exists between cough severity and quality of life (QoL), whether gender difference is implied in the effect of cough on QoL has not been studied yet. This study primarily aims to investigate whether the association between cough severity and QoL is modified by gender in patients with postinfectious cough.

Methods: Secondary analyses were performed in 180 participants with postinfectious cough in a multisite randomized controlled trial. Baseline demographics, clinical characteristics and score of cough specific quality of life questionnaire (CQLQ) were collected. Linear regression analyses were conducted to examine gender difference in CQLQ score and the association between cough severity and CQLQ score.

Results: Difference between women and men was not significant in CQLQ total score in the unadjusted analysis ( $P=0.077$ ). Women had a 2.20-point higher CQLQ total score than men (95\% confidence interval (CI) 0.11-4.30; $P=0.039$ ), after adjusting for age, cough duration, cough severity, and clinical center. Gender significantly modified the association between cough severity and CQLQ total score (coefficient 1.80, 95\% Cl 0.29-3.30; $P=0.020$ ), after adjusting for age, cough duration, and study center. An increase of 1-point in cough severity was associated with a 2.55-point (95\% Cl 1.16-3.95) increase in CQLQ total score in women versus a 1.26-point (95\% Cl 0.20-2.31) increase in men $(P=0.020)$.

Conclusions: Female sex may be associated with worse QoL than men, and women's QoL may be more significantly impaired as cough symptom deteriorates. Gender difference should be taken into account in the clinical settings and research of cough and cough related QoL.

Trial registration: Chinese Clinical Trial Registry, ChiCTRTRC12002297. Registered 19 June 2012, http://www.chictr.org. cn/abouten.aspx.
\end{abstract}

Keywords: Postinfectious cough, Cough specific quality of life, Cough severity, Gender difference

\section{Background}

Cough is among the most common respiratory symptoms that lead patients to seek medical help in primary care and respiratory specialist clinics [1-4]. Although

\footnotetext{
*Correspondence: doc_jhl@163.com

1 Pneumology Group, Department of Integrated Traditional Chinese and Western Medicine, West China Hospital, Sichuan University, No.37 Guoxue Street, Chengdu 610041, China

Full list of author information is available at the end of the article
}

fatal complications are rare, unremitting cough is always frustrating and bothersome. Loss of sleep, exhaustion, irritability, urinary incontinence, cough syncope, social disability, and inability to perform daily activities are some of the negative outcomes associated with considerable distress in patient's daily life and significant impairments in health-related quality of life (QoL) $[5,6]$. With quantitative or semi-quantitative methods, the changes in QoL in cough populations can be accurately analyzed. original author(s) and the source, provide a link to the Creative Commons licence, and indicate if changes were made. The images or other third party material in this article are included in the article's Creative Commons licence, unless indicated otherwise in a credit line to the material. If material is not included in the article's Creative Commons licence and your intended use is not permitted by statutory regulation or exceeds the permitted use, you will need to obtain permission directly from the copyright holder. To view a copy of this licence, visit http://creativecommons.org/licenses/by/4.0/. The Creative Commons Public Domain Dedication waiver (http://creativeco mmons.org/publicdomain/zero/1.0/) applies to the data made available in this article, unless otherwise stated in a credit line to the data. 
Commonly used validated instruments include the Cough Specific Quality of Life Questionnaire (CQLQ) [7], the Leicester Cough Questionnaire [8], and the Chronic Cough Impact Questionnaire [9]. These questionnaires have multiple items and domains and address the impact of cough on various aspects of health-related QoL, including physical, psychological, and social domains [10]. As such, QoL is closely affected by cough severity [11].

Most studies show a higher prevalence of nocturnal and non-productive cough in women than in men [12, 13]. Besides, previous studies have showed that physiology, physiopathology and outcome measures of cough differ in many ways between males and females [14-20]. These could originate from gender-related differences not only in anatomy and physiology of respiratory, immune or nervous system, but also in behavioral and socio-cultural factors that considerably affect respiratory health [21]. However, whether the impact of cough on QoL is also variable between genders is still controversial.

Patients who complain a persistent cough lasting $>3$ weeks after experiencing the acute symptoms of an upper respiratory tract infection may have a postinfectious cough. It is the most common cause of subacute cough, accounting for $30-50 \%$ of patients with subacute symptoms [22, 23]. We recently demonstrated that QingfengGanke granule improved clinical symptoms and cough specific QoL over placebo in patients with postinfectious cough [24]. Although a worse QoL has been reported in women with chronic cough than men [17], a similar cough related QoL between gender is demonstrated during acute conditions such as upper respiratory infections [25]. The gender difference in cough related QoL in subacute cough patients has not been studied yet.

In this post-hoc analysis, we sought to investigate that whether health related QoL was different among women and men, and whether female sex was a modifier in the association between cough severity and QoL among patients with postinfectious cough.

\section{Methods}

\section{Study sample}

The original trial was a multisite randomized controlled trial (Chinese Clinical Trial Registry: ChiCTRTRC 12002297). Detailed study methods had been previously reported [11]. Briefly, a total of 180 eligible participants were randomly assigned to three groups to assess efficacy and safety of a Chinese herbal prescription in patients with postinfectious cough. All patients provided written informed consent and were recruited from five tertiary hospitals across China. The original trial was approved by the Medical Ethics Committee of West China Hospital of Sichuan University (Chengdu, China). Patient enrollment started in April 2011 and ended in March 2012. The current analysis included baseline data of all 180 participants.

\section{Variables}

Demographic variables including gender, age, and marital status were collected; body mass index was calculated based on the reported height and weight; clinical characteristics including previous physician-diagnosis of postinfectious cough, medication use for previous postinfectious cough attack, and cough duration were recorded; cough severity was measured by visual analogue scale (VAS), a widely used tool in clinical research and practice; cough symptom score assessed cough frequency, severity and the overall impact, and was evaluated in terms of daytime and nighttime intervals [26]; health related QoL was assessed using CQLQ at baseline. The questionnaire contains 28 items, each item being scored on a 4-point scale. All these items are summarized into six subscales: physical complaints, psychosocial issues, functional abilities, emotional well-being, extreme physical complaints, and personal safety fears. The score ranges from 28 and 112, with lower scores indicating a better QoL [7].

\section{Statistical analysis}

Baseline results were presented as mean (standard deviation) or median (interquartile range) for continuous variables as appropriate, and frequency (percentage) for categorical variables. Characteristics of women and men were compared using two-sample $t$ test or Mann-Whitney $U$ test for continuous variables and chi-square test for categorical variables.

Cough VAS and cough duration were included in the multiple linear regression model, based on their known or potential impact on QoL [25, 27, 28]. Clinical center was additionally adjusted for possible clustering effects. As current smokers and recent ex-smokers were excluded from the trial, smoke status was not included as a covariate. Daytime and nighttime cough symptom scores were also not included in the model because they captured cough severity and overall impact and might highly correlated with cough VAS. The interactions between gender and cough VAS in the association of total CQLQ were analyzed in the above-mentioned models. The multivariate linear regression analyses were repeated to assess the interaction between gender and cough VAS in the association of six subscales. Regression diagnostics were performed to examine the fit, multicollinearity and potentially influential observations. 
A two-tailed $P$ value $<0.05$ was considered statistically significant. All analyses were performed using IBM SPSS Statistics version 21.0 (IBM, Armonk, NY).

\section{Results}

Demographic and clinical characteristics

A total of 104 women and 76 men were included in this study. There was no significant gender difference in age, body mass index and marital status. Women had longer cough duration than men did (32.6 days vs. 29.3 days, $P=0.035$ ). Previous postinfectious cough history, medication use for previous cough attack, daytime and nighttime cough symptom score, cough VAS and CQLQ total score were not significantly different between women and men. The detailed demographics and clinical characteristics between women and men were shown in Table 1 .

\section{Gender difference in QoL}

A higher mean score of extreme physical complaints was reported in women (9.0 vs. 8.1, $P<0.001)$. The difference between women and men was not significant in the score of total CQLQ and other five subscales in unadjusted analyses (Table 1). Women had a mean of 2.20-point higher CQLQ total score than men (95\% confidence interval (CI) 0.11-4.30; $P=0.039$ ), after adjusting for age, cough duration, cough VAS, and clinical center $\left(R^{2}=0.297\right)$. Female sex was significantly associated with a 0.88 -point increase in extreme physical complaints score compared to men in the adjusted analysis (95\% CI $0.47-1.28 ; P<0.001)$. No significant difference between women and men was found in the other subscales analyses. Detailed differences in women versus men in the score of total CQLQ and six subscales in unadjusted and adjusted analyses were shown in Table 2.

\section{Gender difference in the association between cough severity and QoL}

The association between cough VAS and CQLQ total score was marginally significantly different between women and men in unadjusted analysis (coefficient 1.67, 95\% CI -0.02-3.36; $P=0.053$ ). After adjusting for age, cough duration, and study center, gender significantly modified the association between cough VAS and CQLQ total score (coefficient 1.80, 95\% CI 0.29-3.30; $P=0.020$ ) (Table 3). An increase of 1-point in cough severity assessed by VAS was associated with a 2.55 -point $(95 \%$ CI 1.16-3.95) increase in CQLQ total score in women versus a 1.26 -point $(95 \%$ CI $0.20-2.31)$ increase in men $(P=0.020)$. Women had a higher mean CQLQ total score than men with a similar degree of cough severity (Fig. 1).

Gender difference was significant in the association between VAS and physical complaints (coefficient 0.67, 95\% CI 0.04-1.30; $P=0.038$ ), and psychosocial issues (coefficient $0.48,95 \%$ CI $0.03-0.93 ; P=0.037$ ). After adjusting for age, cough duration, and study center,

Table 1 Characteristics of women and men with postinfectious cough

\begin{tabular}{|c|c|c|c|c|}
\hline Variables & $\begin{array}{l}\text { Overall } \\
(n=180)\end{array}$ & $\begin{array}{l}\text { Women } \\
(n=104)\end{array}$ & $\begin{array}{l}\text { Men } \\
(n=76)\end{array}$ & $P$ value \\
\hline Age (years), mean $\pm S D$ & $44.3 \pm 12.6$ & $45.0 \pm 12.1$ & $43.3 \pm 13.2$ & 0.385 \\
\hline Body mass index $\left(\mathrm{kg} / \mathrm{m}^{2}\right)$, mean $\pm S D$ & $23.4 \pm 3.1$ & $23.1 \pm 3.0$ & $23.8 \pm 3.2$ & 0.131 \\
\hline Married, n (\%) & $157(87.2)$ & $91(87.5)$ & $66(86.8)$ & 0.896 \\
\hline Medication use for previous PIC, n (\%) & $27(15)$ & $20(19.2)$ & $7(9.2)$ & 0.063 \\
\hline Ever previously diagnosed with PIC, n (\%) & $29(16.1)$ & $17(16.3)$ & $12(15.8)$ & 0.920 \\
\hline Cough duration (days), mean \pm SD & $31.2 \pm 9.0$ & $32.6 \pm 9.7$ & $29.3 \pm 7.5$ & 0.035 \\
\hline \multicolumn{5}{|l|}{ Cough symptom score, median (IQR) } \\
\hline Daytime & $2(2,2)$ & $2(2,2)$ & $2(2,2)$ & 0.379 \\
\hline Nighttime & $2(1,2)$ & $2(1,2)$ & $2(1,2)$ & 0.220 \\
\hline Cough VAS, median (IQR) & $6(5,7)$ & $6(5,7)$ & $6(5,7)$ & 0.060 \\
\hline \multicolumn{5}{|l|}{$C Q L Q$, mean $\pm S D$} \\
\hline Total & $64.5 \pm 7.9$ & $65.4 \pm 7.4$ & $63.3 \pm 8.3$ & 0.077 \\
\hline Physical complaints & $21.5 \pm 3.0$ & $21.8 \pm 2.8$ & $21.1 \pm 3.2$ & 0.160 \\
\hline Psychosocial issues & $12.8 \pm 2.1$ & $12.9 \pm 2.0$ & $12.8 \pm 2.3$ & 0.723 \\
\hline Functional abilities & $11.1 \pm 2.0$ & $11.2 \pm 1.9$ & $11.0 \pm 2.2$ & 0.527 \\
\hline Emotional well-being & $7.2 \pm 1.6$ & $7.3 \pm 1.6$ & $7.0 \pm 1.7$ & 0.218 \\
\hline Extreme physical complaints & $8.6 \pm 1.5$ & $9.0 \pm 1.5$ & $8.1 \pm 1.3$ & $<0.001$ \\
\hline Personal safety fears & $6.9 \pm 1.7$ & $7.0 \pm 1.7$ & $6.8 \pm 1.7$ & 0.562 \\
\hline
\end{tabular}

CQLQ cough specific QoL questionnaire, IQR interquartile range, PIC postinfectious cough, VAS visual analogue scale 
Table 2 Gender differences in QoL in unadjusted and adjusted analyses

\begin{tabular}{|c|c|c|c|c|c|c|}
\hline \multirow{3}{*}{$\begin{array}{l}\text { Variables } \\
\text { Total CQLQ }\end{array}$} & \multicolumn{3}{|l|}{ Unadjusted } & \multicolumn{3}{|l|}{ Adjusted } \\
\hline & \multirow{2}{*}{$\begin{array}{l}\text { Coefficient } \\
-2.10\end{array}$} & \multicolumn{2}{|l|}{$95 \% \mathrm{Cl}$} & \multirow{2}{*}{$\begin{array}{l}\text { Coefficient } \\
2.20^{*}\end{array}$} & \multicolumn{2}{|l|}{$95 \% \mathrm{Cl}$} \\
\hline & & -0.23 & 4.42 & & 0.11 & 4.30 \\
\hline Physical complaints & 0.63 & -0.25 & 1.51 & 0.63 & -0.13 & 1.38 \\
\hline Functional abilities & 0.19 & -0.41 & 0.80 & 0.36 & -0.22 & 0.95 \\
\hline Psychosocial issues & 0.11 & -0.51 & 0.73 & 0.24 & -0.34 & 0.81 \\
\hline Emotional well-being & 0.31 & -0.18 & 0.80 & 0.38 & -0.11 & 0.88 \\
\hline Extreme physical complaints & $0.91^{*}$ & 0.50 & 1.33 & $0.88^{*}$ & 0.47 & 1.28 \\
\hline Personal safety fears & 0.15 & -0.36 & 0.65 & -0.09 & -0.54 & 0.37 \\
\hline
\end{tabular}

${ }^{*} P<0.05$

Table 3 Gender differences in association between VAS and QoL

\begin{tabular}{|c|c|c|c|c|}
\hline Variables & Women & Men & Interaction & $P$ value \\
\hline \multicolumn{5}{|l|}{ Total CQLQ } \\
\hline Unadjusted & $2.40(1.04,3.76)$ & $0.73(-0.32,1.78)$ & $1.67(-0.02,3.36)$ & 0.053 \\
\hline Adjusted & $2.55(1.16,3.95)$ & $1.26(0.20,2.31)$ & $1.80(0.29,3.30)$ & 0.020 \\
\hline \multicolumn{5}{|c|}{ Physical complaints } \\
\hline Unadjusted & $0.99(0.48,1.50)$ & $0.32(-0.07,0.71)$ & $0.67(0.04,1.30)$ & 0.038 \\
\hline Adjusted & $1.12(0.58,1.66)$ & $0.58(0.21,0.94)$ & $0.76(0.21,1.30)$ & 0.006 \\
\hline \multicolumn{5}{|c|}{ Functional abilities } \\
\hline Unadjusted & $0.59(0.23,0.96)$ & $0.37(0.11,0.63)$ & $0.23(-0.20,0.66)$ & 0.301 \\
\hline Adjusted & $0.37(-0.04,0.77)$ & $0.34(0.05,0.63)$ & $0.17(-0.26,0.59)$ & 0.445 \\
\hline \multicolumn{5}{|c|}{ Psychosocial issues } \\
\hline Unadjusted & $0.66(0.29,1.03)$ & $0.18(-0.10,0.46)$ & $0.48(0.03,0.93)$ & 0.037 \\
\hline Adjusted & $0.73(0.35,1.11)$ & $0.23(-0.06,0.52)$ & $0.42(0.01,0.84)$ & 0.045 \\
\hline \multicolumn{5}{|c|}{ Emotional well-being } \\
\hline Unadjusted & $-0.02(-0.32,0.28)$ & $0.02(-0.21,0.25)$ & $-0.04(-0.41,0.33)$ & 0.839 \\
\hline Adjusted & $-0.12(-0.47,0.23)$ & $0.04(-0.21,0.29)$ & $-0.00(-0.37,0.36)$ & 0.985 \\
\hline \multicolumn{5}{|c|}{ Extreme physical complaints } \\
\hline Unadjusted & $0.19(-0.04,0.42)$ & $0.03(-0.18,0.24)$ & $0.16(-0.16,0.47)$ & 0.322 \\
\hline Adjusted & $0.24(-0.01,0.50)$ & $0.14(-0.08,0.36)$ & $0.20(-0.10,0.50)$ & 0.185 \\
\hline \multicolumn{5}{|c|}{ Personal safety fears } \\
\hline Unadjusted & $0.02(-0.28,0.32)$ & $-0.23(-0.47,0.01)$ & $0.25(-0.12,0.63)$ & 0.185 \\
\hline Adjusted & $0.18(-0.14,0.50)$ & $-0.12(-0.35,0.11)$ & $0.36(0.03,0.69)$ & 0.034 \\
\hline
\end{tabular}

gender difference was significant in the associations between VAS and physical complaints (coefficient 0.76, 95\% CI $0.21-1.30 ; P=0.006$ ), psychosocial issues (coefficient 0.42 , 95\% CI $0.01-0.84 ; P=0.045)$, and personal safety fears (coefficient $0.36,95 \%$ CI $0.03-0.69 ; P=0.034$ ) (Table 3).

\section{Discussion}

To our knowledge, this study is the first attempt to examine gender difference in QoL and the association between cough VAS and QoL among patients with postinfectious cough. We found that female sex was associated with worse QoL than men, and female sex was a modifier in the association between cough severity and QoL among postinfectious cough patients.

The current study showed that an increase of 1-point cough VAS score was associated with a higher CQLQ total score in women than that in men, after adjusting for age, cough duration, and clinical center. To the 


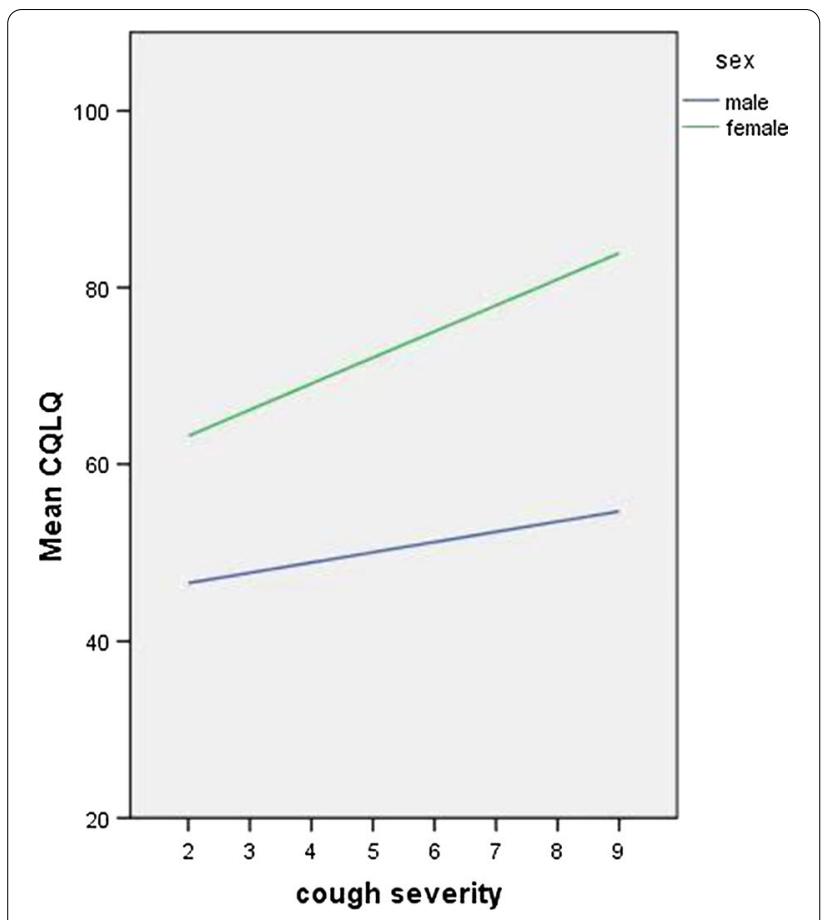

Fig. 1 Association between cough severity and mean CQLQ total score between different genders

best of our knowledge, this is the first study to report this association. The greater effect of cough on QoL in women may be due to higher scores in physical complaints, psychosocial issues, and personal safety fears. Coughing also causes other stressful and unpredictable occurrences, such as stress urinary incontinence, which is currently a social disease and predominantly affects women, leading to considerable physical and psychological morbidities [29, 30].

Although cough lasted longer in women than men, the change in CQLQ total score that was associated with one day increase in cough duration was not significantly different between women versus men in either unadjusted or adjusted analyses (data not shown). The lack of gender difference in the association between cough duration and CQLQ scores suggested that female gender might be not associated with worse QoL as cough lasted longer in postinfectious cough condition, which might be explained by the self-limiting property of postinfectious cough [31].

Inherent to the nature of the secondary analysis of existing data, our study has several limitations that warrant further discussions. First, cough frequency was not collected for the original analysis and therefore, was not included in the adjusting models. This unmeasured variable might confound the relationships addressed and, thus, result in a source of possible bias. Although the impact of objective cough frequency on health related QoL has been considered to be mild to moderate [32, 33], whether their association is different between women and men needs to be further investigated. Second, this study only included 180 patients among five sites in the same country. A larger sample size with more sites that distributed across different countries and regions would provide a more robust result allowing to uncover gender difference in the association between cough severity and QoL.

\section{Conclusions}

Among patients with postinfectious cough, women may experience worse QoL than men, and their QoL may be more markedly affected by cough symptom. Clinicians should be aware of the greater impact of cough on QoL in women, therefore, gender difference should be taken into account in the study of cough and cough related QoL.

\section{Abbreviations}

Cl: Confidence interval; CQLQ: Cough specific quality of life questionnaire; QoL: Quality of life; VAS: Visual analogue scale.

\section{Acknowledgements}

Not applicable.

\section{Authors' contributions}

WL and HJ: Conceptualization, Methodology, Resources, Software, Formal analysis. WL, HJ and QW: Writing —original draft. HJ and BM: Supervision, Validation, Writing — review and editing. All authors read and approved the final manuscript.

\section{Funding}

This work was supported by the National Natural Science Foundation of China [Grant Numbers: 81900039 and 81700024], the China Postdoctoral Science Foundation Grant (Grant Number: 2018M643505), and the Post-Doctor Research Project, West China Hospital, Sichuan University (Grant Number: 2018HXBH039).

\section{Availability of data and materials}

Not applicable.

\section{Ethics approval and consent to participate}

The original trial was approved by the Medical Ethics Committee of West China Hospital of Sichuan University (Chengdu, China). All participates agreed to participate and signed the written consent forms.

\section{Consent for publication}

Not applicable.

\section{Competing interests}

The authors declare that they have no competing interests.

\section{Author details}

${ }^{1}$ Pneumology Group, Department of Integrated Traditional Chinese and Western Medicine, West China Hospital, Sichuan University, No.37 Guoxue Street, Chengdu 610041, China. ${ }^{2}$ Health Management Center, West China Hospital, Sichuan University, No.37 Guoxue Street, Chengdu 610041, China. ${ }^{3}$ Department of Pulmonary Diseases, State Key Laboratory of Biotherapy of China, West China Hospital, Sichuan University, 1 Keyuansi Road, Chengdu 610041, China. 
Received: 21 February 2020 Accepted: 15 January 2021

Published online: 26 January 2021

\section{References}

1. Frese T, Mahlmeister J, Deutsch T, Sandholzer H. Reasons for elderly patients GP visits: results of a cross-sectional study. Clin Interv Aging. 2016;11:127-32.

2. Månsson J, Nilsson G, Strender LE, Björkelund C. Reasons for encounters, investigations, referrals, diagnoses and treatments in general practice in Sweden - a multicentre pilot study using electronic patient records. Eur J Gen Pract. 2011;17:87-94.

3. Axelsson M, Lindberg A, Kainu A, Rönmark E, Jansson SA. Respiratory symptoms increase health care consumption and affect everyday life-a cross-sectional population-based study from Finland, Estonia, and Sweden. Eur Clin Respir J. 2016;3:31024.

4. Young EC, Smith JA. Quality of life in patients with chronic cough. Ther Adv Respir Dis. 2010;4:49-55.

5. Chamberlain SA, Garrod R, Douiri A, Masefield S, Powell P, Bücher C, Pandyan A, Morice AH, Birring SS. The impact of chronic cough: a crosssectional European survey. Lung. 2015;193:401-8.

6. Dicpinigaitis PV, Eccles R, Blaiss MS, Wingertzahn MA. Impact of cough and common cold on productivity, absenteeism, and daily life in the United States: ACHOO Survey. Curr Med Res Opin. 2015;31:1519-25.

7. French CT, Irwin RS, Fletcher KE, Adams TM. Evaluation of a cough-specific quality-of-life questionnaire. Chest. 2002;121:1123-31.

8. Birring SS, Prudon B, Carr AJ, Singh SJ, Morgan MD, Pavord ID. Development of a symptom specific health status measure for patients with chronic cough: Leicester Cough Questionnaire (LCQ). Thorax. 2003:58:339-43

9. Baiardini I, Braido F, Fassio O, Tarantini F, Pasquali M, Tarchino F, Berlendis A, Canonica GW. A new tool to assess and monitor the burden of chronic cough on quality of life: Chronic Cough Impact Questionnaire. Allergy. 2005;60:482-8.

10. Vernon M, Leidy NK, Nacson A, Nelsen L. Measuring cough severity: perspectives from the literature and from patients with chronic cough. Cough. 2009;5:5.

11. Kelsall A, Decalmer S, Webster D, Brown N, McGuinness K, Woodcock A, Smith J. How to quantify coughing: correlations with quality of life in chronic cough. Eur Respir J. 2008;32:175-9

12. Björnsson $E$, Plaschke $P$, Norrman $E$, Janson C, Lundbäck B, Rosenhall A, Lindholm N, Rosenhall L, Berglund E, Boman G. Symptoms related to asthma and chronic bronchitis in three areas of Sweden. Eur Respir J. 1994;7:2146-53.

13. Lúdvíksdóttir D, Björnsson E, Janson C, Boman G. Habitual coughing and its associations with asthma, anxiety, and gastroesophageal reflux. Chest. 1996;109:1262-8.

14. Fujimura M, Kasahara K, Kamio Y, Naruse M, Hashimoto T, Matsuda T. Female gender as a determinant of cough threshold to inhaled capsaicin. Eur Respir J. 1996:9:1624-6.

15. Dicpinigaitis PV, Rauf $K$. The influence of gender on cough reflex sensitivity. Chest. 1998;113:1319-21.

16. Dicpinigaitis PV, Allusson VR, Baldanti A, Nalamati JR. Ethnic and gender differences in cough reflex sensitivity. Respiration. 2001;68:480-2.

17. French CT, Fletcher KE, Irwin RS. Gender differences in health-related quality of life in patients complaining of chronic cough. Chest. 2004;125:482-8.
18. Birring SS, Pavord ID. Assessment of gender differences in health status with the Leicester Cough Questionnaire (LCQ). Thorax. 2009;64:1008-9.

19. Kelsall A, Decalmer S, McGuinness K, Woodcock A, Smith JA. Sex differences and predictors of objective cough frequency in chronic cough. Thorax. 2009;64:393-8.

20. Lamprecht B, Vanfleteren LE, Studnicka M, Allison M, McBurnie MA, Vollmer WM, Tan WC, Nielsen R, Nastalek P, Gnatiuc L, et al. Sex-related differences in respiratory symptoms: results from the BOLD Study. Eur Respir J. 2013;42:858-60.

21. Becklake MR, Kauffmann F. Gender differences in airway behaviour over the human life span. Thorax. 1999;54:1119-38.

22. Kwon NH, Oh MJ, Min TH, Lee BJ, Choi DC. Causes and clinical features of subacute cough. Chest. 2006;129:1142-7.

23. Lai K, Lin L, Liu B, Chen R, Tang Y, Luo W, Chen Q. Eosinophilic airway inflammation is common in subacute cough following acute upper respiratory tract infection. Respirology. 2016;21:683-8.

24. Jiang $H$, Mao B, Wang $L$, Zhang $R$, She B, Jin F, Xu Y, Ma J, Liu Q. The efficacy of QingfengGanke granule in treating postinfectious cough in pathogenic wind invading lungs syndrome: a multicenter, randomized, double-blind, placebo-controlled trial. Chin Med. 2015;10:21.

25. French $C T$, Fletcher $K E$, Irwin RS. A comparison of gender differences in health-related quality of life in acute and chronic coughers. Chest. 2005;127:1991-8.

26. Wang MY, Liu H. The Chinese national guidelines on diagnosis and management of cough (December 2010). Chin Med J (Engl). 2011; 124:3207-19.

27. Lechtzin N, Hilliard ME, Horton MR. Validation of the Cough Quality-ofLife Questionnaire in patients with idiopathic pulmonary fibrosis. Chest. 2013;143:1745-9.

28. Wang K, Birring SS, Taylor K, Fry NK, Hay AD, Moore M, Jin J, Perera R, Farmer A, Little P, et al. Montelukast for postinfectious cough in adults: a double-blind randomised placebo-controlled trial. Lancet Respir Med 2014:2:35-43.

29. Hannestad YS, Rortveit G, Sandvik H, Hunskaar S. A community-based epidemiological survey of female urinary incontinence: the Norwegian EPINCONT study. Epidemiology of Incontinence in the County of NordTrøndelag. J Clin Epidemiol. 2000;53:1150-1157.

30. Fultz NH, Burgio K, Diokno AC, Kinchen KS, Obenchain R, Bump RC. Burden of stress urinary incontinence for community-dwelling women. Am J Obstet Gynecol. 2003;189:1275-82.

31. Braman SS. Postinfectious cough: ACCP evidence-based clinical practice guidelines. Chest. 2006;129:138s-46s.

32. Schmit KM, Coeytaux RR, Goode AP, McCrory DC, Yancy WS Jr, Kemper AR, Hasselblad V, Heidenfelder BL, Sanders GD. Evaluating cough assessment tools: a systematic review. Chest. 2013;144:1819-26.

33. Birring SS, Matos S, Patel RB, Prudon B, Evans DH, Pavord ID. Cough frequency, cough sensitivity and health status in patients with chronic cough. Respir Med. 2006;100:1105-9.

\section{Publisher's Note}

Springer Nature remains neutral with regard to jurisdictional claims in published maps and institutional affiliations.

Ready to submit your research? Choose BMC and benefit from

- fast, convenient online submission

- thorough peer review by experienced researchers in your field

- rapid publication on acceptance

- support for research data, including large and complex data types

- gold Open Access which fosters wider collaboration and increased citations

- maximum visibility for your research: over 100M website views per year

At $\mathrm{BMC}$, research is always in progress.

Learn more biomedcentral.com/submissions 